\title{
HOW DO SMART BUILDING PROJECTS DEFINE AND DELIVER VALUE? \\ A CLASSIFICATION OF BUSINESS MODELLING CHARACTERISTICS TO SUPPORT DESIGN AND DEVELOPMENT
}

\author{
Adriano Tanda and Alberto De Marco \\ Politecnico di Torino, Department of Management and Production Engineering \\ Corso Duca degli Abruzzi 24, 10129, Torino
}

\begin{abstract}
Both public administrations and real estate developers have been investing in innovative Smart Building projects to reduce energy consumption while improving housing quality and occupant comfort. Despite a booming market and an ever-growing academic interest in Smart Building technologies, few studies are available to understand the value generated by Smart Building projects and how these initiatives are able to achieve business success and distribute value to their stakeholders.

To fill this gap, this study presents an empirical analysis of 300 Smart Building projects implemented internationally. The projects' characteristics have been analyzed on a business model framework in order to identify general concepts and discarding redundant information. The result of this effort has been a classification of business modelling characteristics able to illustrate the main value and business objectives pursued by Smart Buildings projects and the strategies through which these projects distribute and deliver value to their customers and stakeholders.

This study presents two main implications. First, it helps scholars in their study on the development and implementation of Smart Building projects. Second, it supports the decision-making processes of both public and private developers acting as a collection of best practices for the design and development of Smart Building initiatives.
\end{abstract}

\section{KEYWORDS}

Smart City, Intelligent Buildings, Smart Buildings, Business Models, Case Study

\section{INTRODUCTION}

In 2017 the world's population exceeded 7.5 billion people and will grow up to 9.77 billion by 2050 (United Nations, 2017). One of the direct consequences of this trend is the ever-growing need for greater housing capacity and new buildings. On average, between 20 and $40 \%$ of the world's energy consumption is due to buildings (Arditi et al., 2015) making them the source of $40 \%$ of the annual Green House Gas (GHG) emissions (Kleissl and Agarwal 2010), and accounting from 5 to $10 \%$ of an average firm operating cost (Ghayvat et al., 2015). Furthermore, occupant comfort and quality of life is of paramount importance as it is linked to higher satisfaction and productivity (Holopainen et al., 2014). Indeed, housing quality correlates to psychological well-being (Wilner et al., 1962), improved children school performances, and has a positive effect on occupant depression and anxiety (Elton and Packer,1986). The Smart City (SC) and in particular Smart Buildings (SB) have been emerging as paradigms whose goals are fostering urban economic and social growth, guaranteeing the city's global competitiveness, and improving its environmental sustainability and the quality of life of its citizens (Michelucci et al., 2016) (Caragliu et al., 2011). Given these considerations, it is not surprising that the market for SB technological solutions is booming (Tanda and De Marco, 2018a) with Garner Insight (2018) reporting that by 2023 the market for these technologies will reach $\$ 31.74$ billion from the $\$ 7.42$ of 2018 . 
Nevertheless, there is a scarcity of studies investigating how SB initiatives are able to create value. The majority of these seminal works address these topics from a business modelling perspective (Tanda and De Marco, 2018b) as it considered to be the best tool to describe how an organization creates, captures, and delivers value (Osterwalder and Pigneur, 2010). Even fewer studies focus on developing a prescriptive approach to the topic by presenting classifications and taxonomies of SC business models. It is the case, for example, of Perboli et al. (2014) who develop a taxonomy of SC projects' business model characteristics based on a case study analysis of 28 SC initiatives or Cledou et al. (2018) who synthesize the business model characteristics of 42 SC services on a taxonomic framework describing how these initiatives are designed and developed.

However, these approaches present several criticalities. First, the related literature is quite limited, and the approaches presented are heterogeneous. Furthermore, no one presents a comprehensive approach to the topic, which should address together both value creation and stakeholder relationships. Finally, these focus on single vertical SC domain, mostly ignoring the building domain and SB technologies. As a contribution to filling these literature gaps, this study aims to address the following question: how do SB initiatives define and deliver value?

To answer this question, the goal of this work is to study the value creation processes of SB projects and services and develop a classification of their business model characteristics able to describe:

- Which value SB projects aim to deliver;

- How the intended value is created and distributed in relationship with projects' stakeholders;

To this end, the author collected 300 world-wide distributed SB projects focusing on small scale self-contained initiatives in order to capture a finer level of detail. For each of these projects, the author has synthesized their characteristics into a classification framework. This study will provide a tool able to assist academics in their studies on SB projects and aid city managers and private organizations in their decision-making processes designing, developing, and implementing SB projects.

This study is structured as follows. First, an overview of the literature is given (Section 2). Second, the methodology is explained (Section 3). Then, results are presented and discussed (Section 4). Finally, the authors draw conclusions and underline implications and limitations (Section 5).

\section{LITERATURE OVERVIEW}

Buildings are increasingly integrating technological systems in order to become "smart" (Arditi et al, 2015). Modern information and communication technologies allow the integration of control platforms to monitor and control buildings' infrastructures (Minoli et al., 2017) providing for a more efficient and cost-effective building ownership (So et al. 1999) and a more comfortable living experience by achieving the optimal combination of comfort and resource consumption (Chen et al., 2013) (Kwon et al., 2014). Intelligent solutions can be implemented in order to remotely control monitoring and automating the operations, performances and consumptions of a building HVAC system (Kolokotsa et al.2011), with the goal of reducing energy, eliminate wastes and improve comfort (Weng and Agarwal 2012). Similar technologies can be deployed in order to automate the operation of a building's lighting system, monitor its status and consumption and remotely control it (Tao et al., 2016). Similarly, the building's plumbing and irrigation system can also be remotely controlled, monitored, and automated in order to reduce water consumption and wastes (Kleissl and Agarwal 2010) (Minoli et al., 2017) while monitoring and controlling lifts and elevators guarantee a higher level of operational efficiency and safety (Arditi et al., 2015). Sensing technologies can also be implemented to monitor and control the building environment with the overall goal of improving the living comfort and the residents' well-being (Kwon et al., 2014). Indeed, all the buildings' air and water quality parameters, such as air and water temperature, air pollutants, humidity and noise pollution can all be easily monitored (Doukas et al. 2007). Remote control systems can also guarantee a higher degree of resident safety thanks to modern security and automatic access control systems (Doukas et al. 2007) (Ghayvat et al., 2015). Finally, new technologies can provide faster and more effective systems for fire prevention, detection, and extinguishment (Doukas et al. 2007). 
Considering the vast field of applications, the authors decided to implement the taxonomic definition in Neirotti et al. (2014) who define of the domain "buildings" by breaking it down into three main sub-domains:

- Facility Management (FM): technologies and services aimed at improving aspects related to cleaning, maintenance, and property management;

- Building Services (BS): technologies and services for improving buildings' existing infrastructures such as electric networks, elevators, fire safety, telecommunication, centralized HVAC, and water supply systems;

- Housing Quality (HQ): technological solutions related to house automatization and the quality of life in a residential housing such as comfort, lighting, and safety;

\section{METHODOLOGY}

The authors developed a qualitative inductive data analysis approach with the objective of using data in order to extract theory (Glaser and Strauss, 2017). In particular, this study is based on a multiple case-study methodology, as it is a collective "robust" and "reliable" method (Baxter and Jack, 2008) most appropriate when researching the "why" and "how" of a contemporary issue or set of events (Johnson, 2008), followed by the empirical analysis of gathered data.

\subsection{Data Gathering}

The data gathering process was based on the definitions given in the previous section. To avoid the classical weaknesses of a single-case (holistic) model (Yin. 2013) such as lack of statistical significance and, most importantly, selection biases, for each of the three listed sub-domains, the author collected and analyzed 100 projects, for a total of 300 internationally distributed projects. This number was found sufficient in saturating the sample (O'Reilley and Parker, 2012). The research process has been conducted on the Internet by searching, on the search engine Google, for a query composed as follows: "name of the sub domain" AND "case study". The result of this search process allowed the author to gather projects from multiple sources such as: project reports to funding bodies, company websites and press releases, case-study white papers, and minutes of city council meetings. The multitude of different sources allow to confirm the validity of the process (Yin, 2013) and enhance the credibility of the study (Baxter and Jack, 2008). To populate the sample, the authors selected only the projects having the following characteristics:

- Small-scale and contained;

- Were, currently are, or are planned to be implemented, and/or are or have been commercially available;

- With enough information available in order to evaluate their business model characteristics;

Figure 1 shows the geographical distribution of the sample by international region, while Figure 2 shows their year of implementation. From Figure 1 is it possible to notice that most projects can be found either in Europe or North America. Furthermore, despite the data gathering process not being limited to a specific timeframe to avoid potential recency biases, from Figure 2 it is possible to observe that the overwhelming majority of projects have been implemented in the last ten years, between 2008/2009 and 2019/2020, highlighting the dramatic impact that recent technological advancements had on the development of innovative SB solutions (Theodoridis et al., 2018).

\subsection{Framework Design}

The second step of the study has been the development of a framework of main business modelling elements onto which the projects' characteristics can be analyzed and confronted. Given its prominence in the literature on SC business modelling (Schiavone et al, 2019), the author decided to use the business model canvas by Osterwalder and Pigneur (2010) as the reference framework for this study. However, while it allows to understand the value proposed by an organization and how it can deliver that value to its intended targets, it 
does not map two important elements useful to describe how specific projects are developed, namely the project's ownership and the project initial financing source. To this end, the author integrated the business model canvas following the framework model presented by Perboli et al. (2014) where "project initiator" of a SC project is classified as either a public entity, a private organization or a mix of the two, and the "financial resources" of a SC can come from either public or private sources.

\subsection{Analysis}

For the last step, each project has been analyzed individually, and its business model characteristics classified on the framework. The author started by identifying the project's owner and its financing sources. After this preliminary step, the other business model characteristics of the projects have been synthesized on the remaining nine elements of the framework. Finally, the author started an iterative process of refinement to identify similarities between different projects business model characteristics. The result has been the emergence of general concepts and patterns (Baden-Fuller and Morgan, 2010) that captured the essence of the projects' value creation process while discarding redundant information.

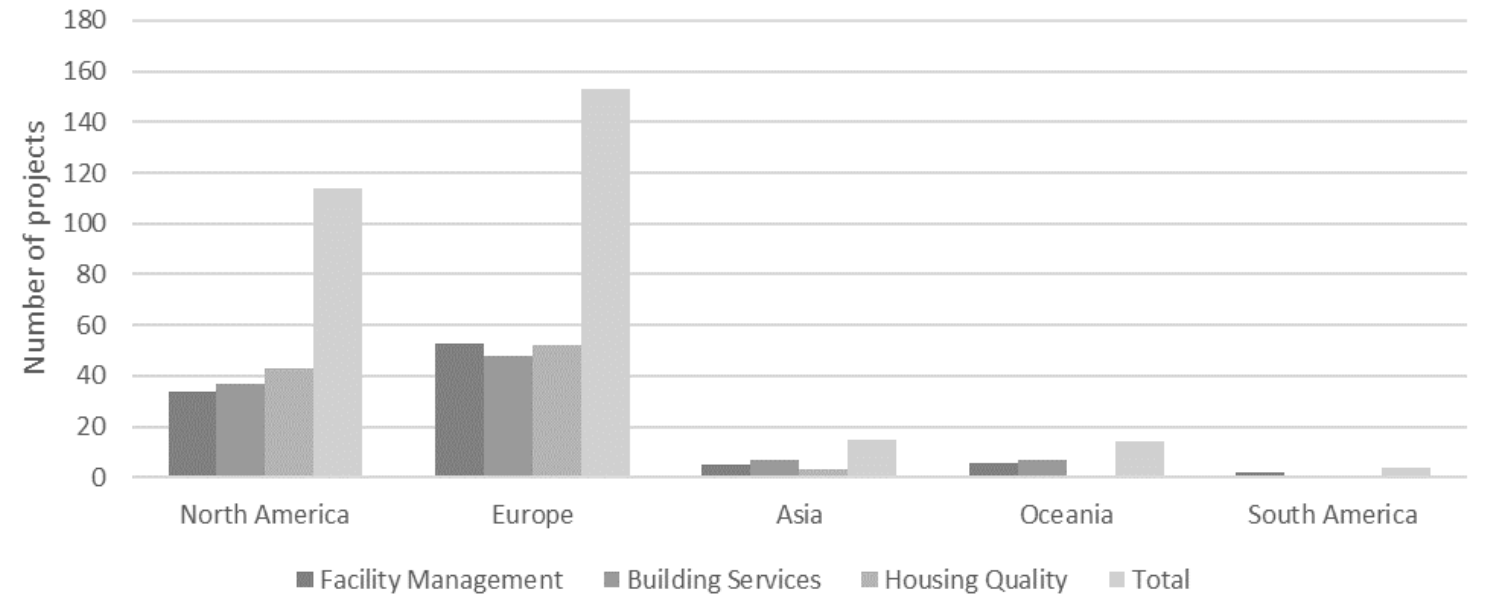

Figure 1. Geographical distribution of SB projects

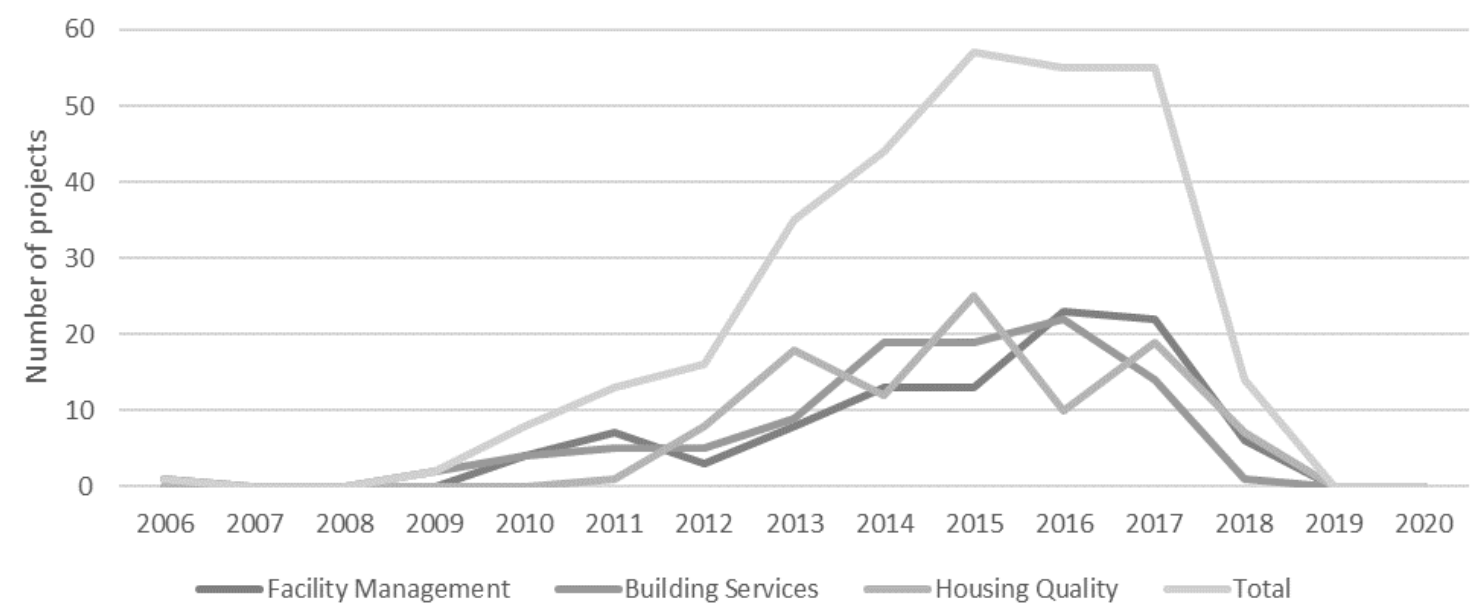

Figure 2. Implementation year of SB projects 


\section{DISCUSSION OF RESULTS}

\subsection{Facility Management}

Chotipanich (2004) argues that the main role of FM is to support business operations and activities while managing human resources and the work environment through an efficient management of resources and services. Hence, the value propositions that can be observed in Table 1 are not surprising. The main objective of FM smart projects is to provide cost savings: $71 \%$ of FM projects aim to reduce operations costs by improving efficiency and productivity, consistently with FM acting as a key support for businesses' operations, while $49 \%$ of FM projects aim to increase energy efficiency. The FM domain involves a wide array of operations (Nutt, 2002) all using different environmental resources. Hence, the second most pursued objective of FM projects (70\%) is to reduce pollution and the environmental impact of the buildings' FM operations.

Table 1. Classification of business modelling characteristics for FM projects

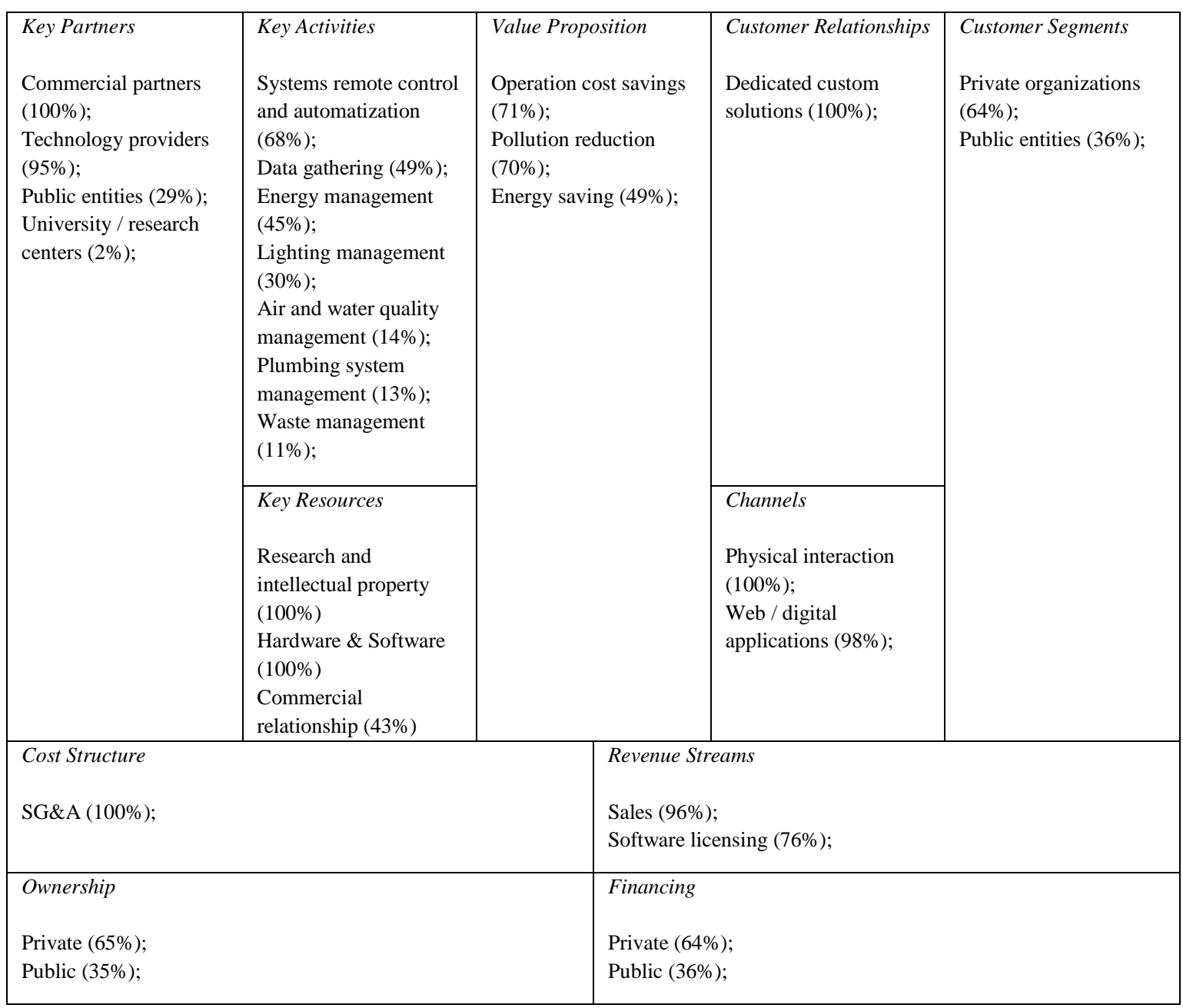

These objectives are achieved through multiple activities. Most FM projects reach their goals through the deployment of systems able to remotely control, program, and automate FM operations (68\%) and able to sense and collect buildings' data (49\%). Direct energy management activities are implemented in $45 \%$ of projects, while $30 \%$ implement solutions to directly manage the building lighting systems. The management of the building's environmental parameters (air and water quality) is pursued by $14 \%$ of projects, while $13 \%$ of FM initiatives are deployed to control and automate the building's water and plumbing infrastructures. Finally, 
$11 \%$ of the projects manage waste and recycling systems. The main targets of FM projects are private organizations (64\%) while $36 \%$ of projects target public entities. There is virtually no overlap between targeted segments as FM projects are developed custom made for a specific customer. Partnerships are key for the implementation of FM projects, both with commercial entities $(100 \%)$ such as retailers, distributors, and technicians, and with technical suppliers (95\%). Public entities are a partner in $29 \%$ of projects. The almost complete lack of partnership with research institutions $(2 \%)$ highlights the technological maturity of these projects. Finally, sources of revenue are quite traditional: the overwhelming majority of FM projects' revenue $(96 \%)$ comes from direct sales of goods and services and $4 \%$ of projects generate revenue through software licensing. This suggest that the market of FM smart solutions tends to have more traditional monetization structures. Finally, while most FM projects are owned and financed by private organizations, a sizeable minority of them are owned and financed by public entities (35 and 36\% respectively) suggesting a relatively high level of involvement of the public sector in the development of these projects.

\subsection{Building Services}

From data reported in Table 2, $66 \%$ of the sample projects have reducing the building environmental impact as one of the main goals, while $57 \%$ aim to improve their energy efficiency. Finally, $51 \%$ of the projects aim at reducing the building operations costs.

Table 2. Classification of business modelling characteristics for BS projects

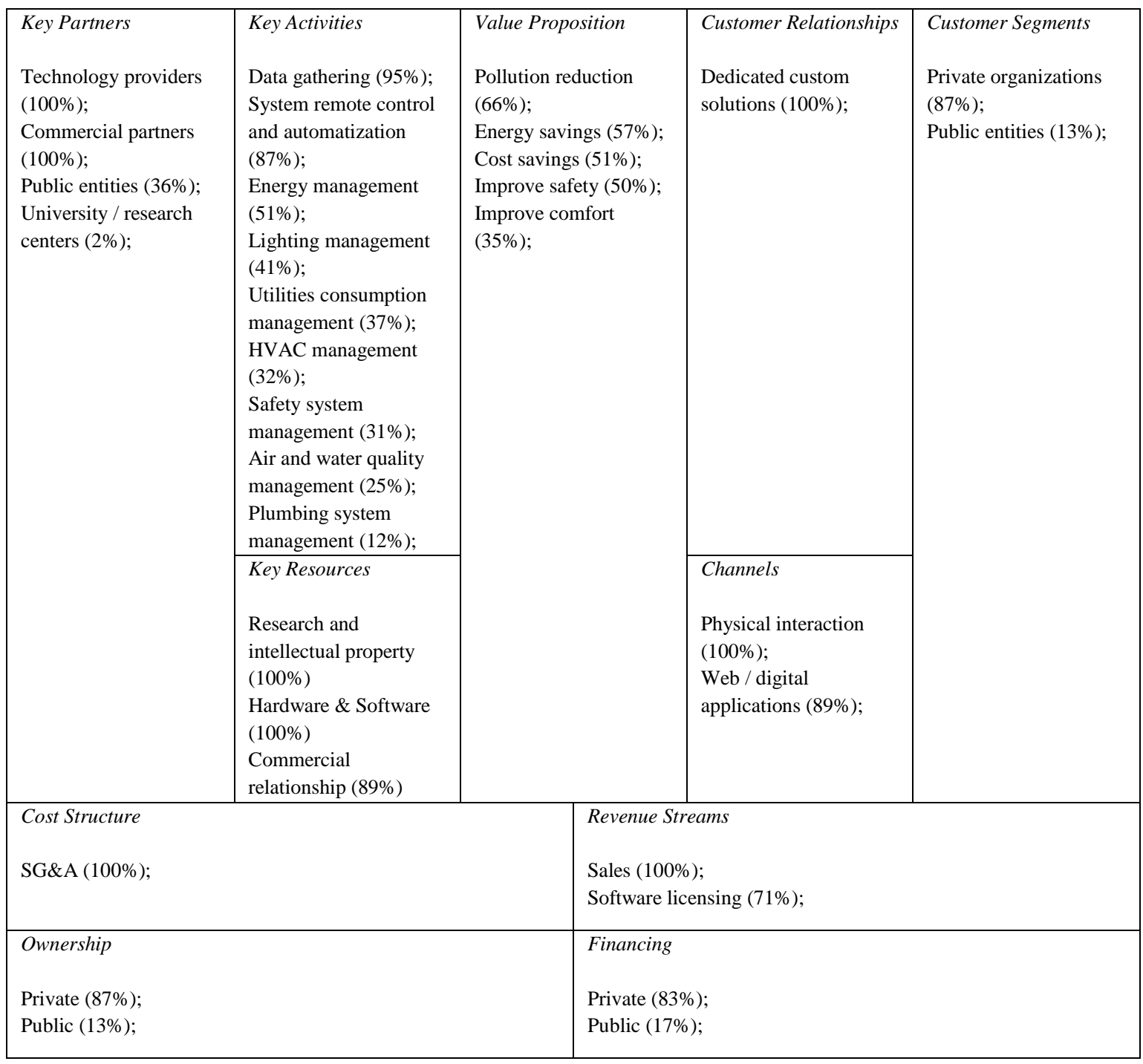


However, safety and security are the main reasons behind the design and development of SB technologies (Ghayvat et al., 2015) (Kleissl and Agarwal 2010). Hence, it is not surprising that improving building security results as the objective of $50 \%$ of the sample projects. Similarly, the main objective of a smart building is to provide a high level of living comfort and wellbeing to its occupants (Doukas et al., 2007) (Kwon et al., 2014). This is reflected in the sampled projects: in fact, improving comfort and resident wellbeing is the main objectives for $35 \%$ of the sample.

BS projects implement technologies able to sense the building environment and remotely and automatically act (95 and 87\% respectively). Other key components of the building infrastructure directly managed by smart solutions are the energy system (51\%), the lighting system (41\%) and the HVAC system (32\%). Finally, together with environmental sensing (the building's air and water quality), security management allows for a direct improvement of the occupant safety. Unsurprisingly, most customers are private organizations (87\%), with public entities target of only $13 \%$ of the projects. Even more than for FM, BS projects are developed for specific customers. This is why the lack of overlapping in the targeted customer segment of these projects is observed. Technology providers and commercial partners are essential for the implementation of BS projects $(100 \%)$, while public entities act as partners in $36 \%$ of the projects. Universities and research centers are almost absent $(2 \%)$, which suggests a strong maturity of these technologies. Finally, it is possible to observe a traditional monetization approach in all the projects with direct sales of goods and services as the main revenue stream. This strengthens the idea that the market of SB solutions is relatively traditional regarding how they make money. Private organizations are the main owners and financiers of BS projects, with the public sector relegated to a minority position.

\subsection{Housing Quality}

As stated above, innovative technologies in the home environment have the objective of improving comfort, energy efficiency, safety and security (Ghayvat et al., 2015). It comes as no surprise then, from the data in Table 3, that improving comfort is by far the most pursued objective for HQ technologies (in $89 \%$ of projects), followed by safety improvements (42\%). Interestingly, HQ projects are less concerned with providing cost saving measures (only $18 \%$ of HQ projects) and reducing the housing environmental impact (24\%) suggesting that HQ projects are driven more by the potential positive impact that they can have on the occupants' quality of life than by cash or environmental considerations.

HQ projects implement a multitude of smart solutions. Systems able to sense and collect building information while automatically react upon these data or allowing for the possibility of remote intervention can be found in a majority of the project sampled (67 and 56\% respectively). $73 \%$ of projects aim to directly manage home lighting, while 58\% manage HVAC systems. Entertainment-oriented solutions are offered in $52 \%$ of projects, while $32 \%$ of the projects offer safety and security technologies. Finally, only a minority of projects deploy technology for energy, consumption and water management $(29,22$, and $22 \%$ respectively). Projects in the HQ domains are related to housing safety and security, and home automation. Hence, these projects mostly target homeowners and private users (100\%). Unsurprisingly then, while technology providers maintain their role as key partners in most HQ projects (98\%), commercial partners lose their relevance (18\%), as most of HQ solutions are distributed through retail and do not require specialist technical support for installation and maintenance. HQ projects present a high degree of maturity, highlighted by the irrelevance of universities or research centers as main partners. Finally, revenue sources for HQ projects come from traditional sales of goods and services (100\%). The public sector appears to be completely absent as either owner or financer of HQ projects, which is reasonable as these projects are targeted at consumers and homeowners. 
Table 3. Classification of business modelling characteristics for HQ projects

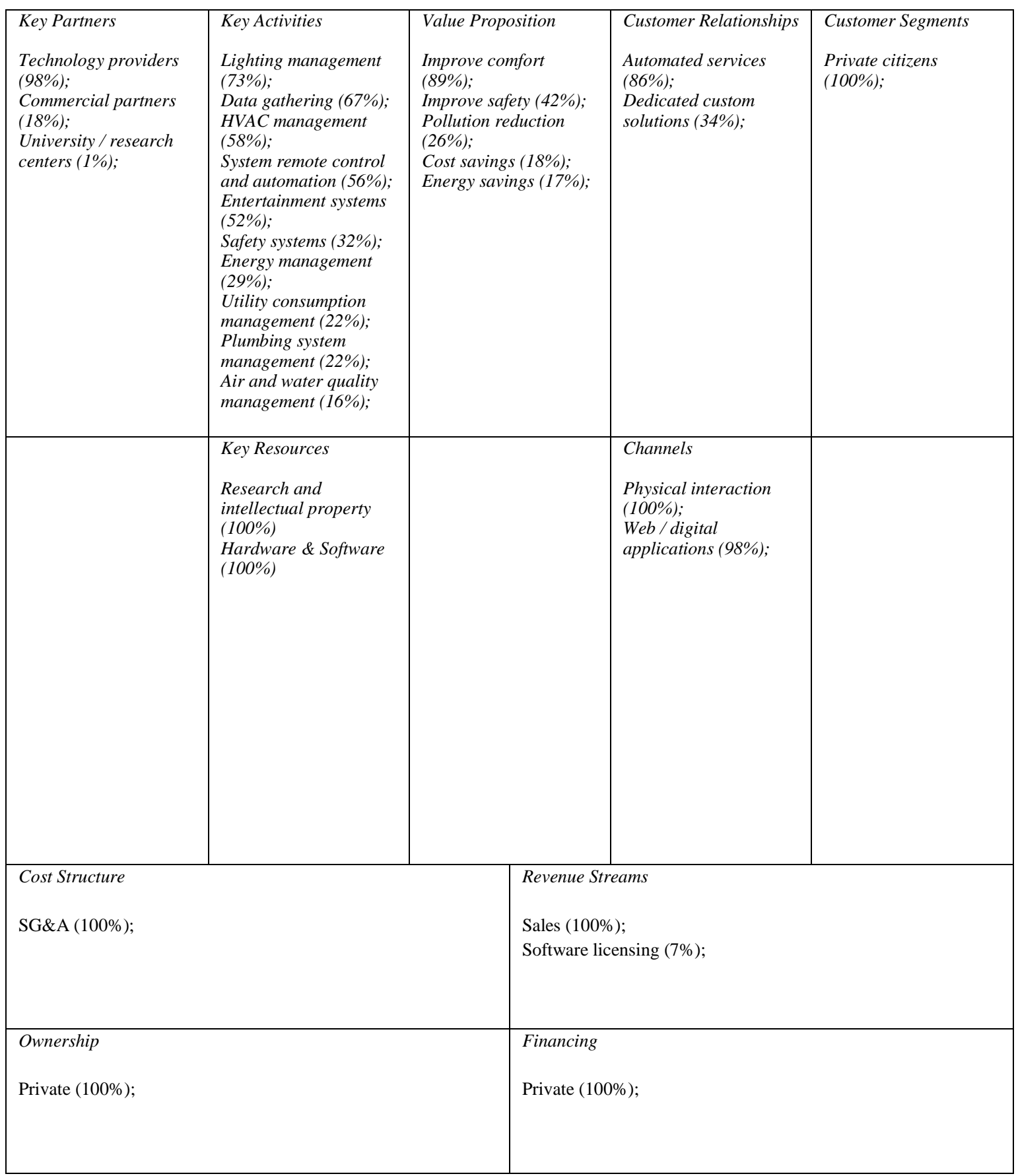

\subsection{Discussion}

From the data discussed above, it is possible to notice that all three SB domains present similar objectives and value propositions, all aiming to reduce costs and pollution while improving energy efficiency, safety and comfort. Furthermore, projects in the SB domains are able to deliver both public and private value and have both business-oriented and socially-conscious objectives. Indeed, cost reduction, energy savings, and comfort are key objectives, highlighting the business-oriented nature of these projects, the main goal appears to be 
reducing pollution, while improving the safety and security of buildings and building services, highlighting their socially-conscious orientation.

This is consistent with the related literature that identify the buildings as the most critical urban dimension in terms of energy consumption and emissions and highlight the possibilities of smart technologies in terms of cost reduction and improved quality of life (Arditi et al., 2015). To summarize, SB projects are able to deliver both socially-conscious public value (Emerson, 2003) and business-oriented objectives. In particular, the main objectives of these projects are reducing pollution and improving occupant's safety and security, while reducing costs and energy consumptions and improving living comfort.

SB projects implements several innovative technologies. Nevertheless, gathering data and implementing systems able to monitor, program and automate building functions, from lighting to the HVAC system, is the main key enabler for SB projects. As most of the projects in the SB domains are at least partially custom made for a specific customer, there are no overlaps between the projects' targets. Private organizations are the major customer for these projects, followed by homeowners and public entities. Partnerships are relatively homogeneous, with technology providers and suppliers, and distributors and technicians being the main key partners.

SB projects present a traditional approach to monetization strategies with sales representing the main revenue source. The lack of research and development as a meaningful cost item highlights the market maturity of these projects, as underlined by the almost total lack of research institutions as partners.

Finally, the public sector plays a minor role as both owner and financing source. However, projects implemented in the SB domains still deliver socially-conscious public value. One explanation for this may be that these objectives are, in reality, a byproduct of a business-oriented pursuit of energy efficiency. However, one other explanation is that the public sector is able to drive this socially-oriented innovation mostly through regulations and guidelines. The role of the public sector becomes to design regulations driving innovative smart building projects with the objective of prompting the implementation of socially-conscious technologies and solutions.

\section{CONCLUSION}

This paper proposes a classification of business modelling characteristics for SB innovative projects that addresses the following research question: how do SB projects define and deliver value?

To this end, the authors have collected 100 projects for each of the three domains composing the SB taxonomy. The business modelling characteristics of each project has been analyzed and classified on the business model canvas by Osterwalder and Pigneur (2010), chosen as a reference framework for this study, to capture the essence of these characteristics.

As a theoretical contribution, this classification is able to address the shortcomings of the academic literature on the design and development of SB projects. This classification helps understand how SB projects create and distribute value and how these structure change depending on the different domain. Therefore, this work presents a reference canvas for the analysis of SB projects and allows scholars to better understand and predict the strategies and decisions required for their implementation.

As a practical implication, this classification helps public administrators effectively and efficiently develop their own SB projects depending on the goals and objectives they aim to achieve. On the other hand, private vendors will be able to use these classifications as a way to discern what benefits are expected by their clients and how to effectively create and deliver it.

This study suffers from two main limitations. First, the overwhelming majority of projects analyzed comes from either Europe or North America. However, this reflects the limitations of the data gathering process due to the author's geographical and language constraints.

Second, by design this study limits the projects' collection to the definitions presented in the literature section. Any SB projects, and their relative characteristics, outside the scope of those definition are not included in the analysis. 


\section{REFERENCES}

D. Arditi et al. (2015) "Assessing the Smartness of Buildings," Facilities 33:9-10, 553-572.

C. Baden-Fuller, M.S. Morgan (2010) "Business Models as Models," Long range planning 43:2-3, 156-171.

P. Baxter, S. Jack, (2009) "Qualitative Case Study Methodology: Study Design and Implementation for Novice Researchers," The qualitative report 13:4, 544-559.

A. Caragliu et al. (2011) "Smart Cities in Europe," Journal of urban technology 18:02, 65-82.

C. Chen et al. (2913) "The User Side of Sustainability: Modeling Behavior and Energy Usage in the Home," Pervasive and Mobile Computing 9:01, 161-175.

G. Cledou et al. (2018) "A Taxonomy for Planning and Designing Smart Mobility Services," Government Information Quarterly 35:1, 61-76.

S. Chotipanich (2014) "Positioning Facility Management," Facilities 22:13-14, 364-372.

H. Doukas et al. (2007) “Intelligent Building Energy Management System Using Rule Sets,” Building and Environment 42:10, 3562-3569.

P. Elton, J. Packer (1986) “A Prospective Randomized Trial of The Value of Rehousing on The Grounds of Mental Health," Journal of Chronic Disease 39, 221-227.

J. Emerson (2003) "The Blended Value Proposition: Integrating Social and Financial Returns," California Management Review 45:4, 35-51.

Garner Insights (2018) Global Smart Buildings Market 2018 by Manufacturers, Countries, Type and Application, Forecast to 2023 https://garnerinsights.com/Global-Smart-Buildings-Market-2018-by-Manufacturers-Countries-Type-andApplication-Forecast-to-2023 Accessed November 12, 2018.

H. Ghayvat et al. (2015) "WSN-and IOT-based Smart Homes and Their Extension to Smart Buildings," Sensors 15:5, 10350-10379.

B. G. Glaser, A. L. Strauss (2017) Discovery of Grounded Theory: Strategies for Qualitative Research (UK, London: Routledge).

R. Holopainen, et al. (2014) "Comfort Assessment in The Context of Sustainable Buildings: Comparison of Simplified and Detailed Human Thermal Sensation Methods," Building and Environment 71:1, 60-70.

W. H. Johnson (2008) "Roles, Resources and Benefits of Intermediate Organizations Supporting Triple Helix Collaborative R\&D: The Case of Precarn", Technovation 28: 8, 495-505.

J. Kleissl, Y. Agarwal (2010) "Cyber-Physical Energy Systems: Focus on Smart Buildings,” paper presented at the Design Automation Conference (DAC) (Anaheim, CA, U.S.A., June 13-18).

D. Kolokotsa et al. (2011) “A Roadmap Towards Intelligent Net Zero and Positive Energy Buildings," Solar Energy 85:2, 3067-3084.

O. Kwon et al. (2014) "Sensor-Aware Elevator Scheduling for Smart Building Environment," Building and Environment, $72: 1,312-326$.

F. V. Michelucci et al. (2016) "Defining the Role of the Smart-City Manager: An Analysis of Responsibilities and Skills," Journal of Urban Technology 23:03, 23-42.

D. Minoli et al. (2017) "IoT Considerations, Requirements, and Architectures for Smart Buildings-Energy Optimization and Next-Generation Building Management Systems," IEEE Internet of Things Journal 4:1, 269-283.

P. Neirotti et al. (2014) "Current Trends in Smart City Initiatives: Some Stylised Facts," Cities 38, 25-36.

B. Nutt (2000), "Four Competing Futures for Facility Management," Facilities 18:3-4,124-132.

M. O'reilly, N. Parker (2012) “'Unsatisfactory Saturation': A Critical Exploration of the Notion of Saturated Sample Sizes in Qualitative Research,” Qualitative Research, 13:2, 190-197.

A. Osterwalder, Y. Pigneur (2010) Business Model Generation, (Hoboken, NJ, USA: Willey).

G. Perboli et al. (2014) “A New Taxonomy of Smart City Projects," Transportation Research Procedia 3, 470-478.

F. Schiavone et al. (2019) "Business Model Innovation for Urban Smartization," Technological Forecasting and Social Change 142, 210-219.

A. T. P. So et al. (1999) “A New Definition of Intelligent Buildings for Asia," Facilities 17:12-13, 485-491.

A. Tanda, A. De Marco (2018a) "Drivers of Public Demand of IoT-Enabled Smart City Services: A Regional Analysis," Journal of Urban Technology 25:4, 77-94.

A. Tanda, A. De Marco (2018b) "Business Model Framework for Smart City Mobility Projects," paper presented at the World Multidisciplinary Civil Engineering-Architecture-Urban Planning Symposium - WMCAUS 2018 (Prague, Czech Republic, June 18-22).

F. Tao et al. (2016) "Internet of Things in Product Life-Cycle Energy Management," Journal of Industrial Information Integration 1, 26-39. 
E. Theodoridis et al. (2013) "Developing an IoT Smart City Framework," paper presented at the 4th International Conference on Information, Intelligence, Systems and Applications (Piraeus, Greece, July 10-12).

United Nations, Department of Economic and Social Affairs, Population Division (2017) World Population Prospects: The 2017 Revision, Volume I: Comprehensive Tables https://esa.un.org/unpd/wpp/Publications/Files/WPP2017_VolumeI_Comprehensive-Tables.pdf Accessed March 13, 2018.

T. Weng, Y. Agarwal (2012) "From Buildings to Smart Buildings-Sensing and Actuation to Improve Energy Efficiency," IEEE Design \& Test of Computers 29:4, 36-44.

D. Wilner et al. (1962) The Housing Environment and Family Life: A Longitudinal Study of the Effects of Housing on Morbidity and Mental Health (Baltimore, MD, U.S.A.: Johns Hopkins Press).

R. K. Yin (2013) Case Study Research and Applications: Design and Methods (Thousand Oaks, CA, U.S.A.: Sage publications, 2013). 